\title{
Developmental Nicotine Exposure Alters AMPA Neurotransmission in the Hypoglossal Motor Nucleus and Pre-Bötzinger Complex of Neonatal Rats
}

\author{
Stuti J. Jaiswal, ${ }^{1}$ Jason Q. Pilarski, ${ }^{2}$ Caitlyn M. Harrison, ${ }^{2}$ and Ralph F. Fregosi ${ }^{1,2}$ \\ Departments of ${ }^{1}$ Neuroscience and ${ }^{2}$ Physiology, University of Arizona, Tucson, Arizona 85721
}

Developmental nicotine exposure (DNE) impacts central respiratory control in neonates born to smoking mothers. We previously showed that DNE enhances the respiratory motor response to bath application of AMPA to the brainstem, although it was unclear which brainstem respiratory neurons mediated these effects (Pilarski and Fregosi, 2009). Here we examine how DNE influences AMPA-type glutamatergic neurotransmission in the pre-Bötzinger complex (pre-BötC) and the hypoglossal motor nucleus (XIIMN), which are neuronal populations located in the medulla that are necessary for normal breathing. Using rhythmic brainstem slices from neonatal rats, we microinjected AMPA into the pre-BötC or the XIIMN while recording from XII nerve rootlets (XIIn) as an index of respiratory motor output. DNE increased the duration of tonic activity and reduced rhythmic burst amplitude after AMPA microinjection into the XIIMN. Also, DNE led to an increase in respiratory burst frequency after AMPA injection into the pre-BötC. Whole-cell patch-clamp recordings of XII motoneurons showed that DNE increased motoneuron excitability but did not change inward currents. Immunohistochemical studies indicate that DNE reduced the expression of glutamate receptor subunits 2 and 3 (GluR2/3) in the XIIMN and the pre-BötC. Our data show that DNE alters AMPAergic synaptic transmission in both the XIIMN and pre-BötC, although the mechanism by which this occurs is unclear. We suggest that the DNE-induced reduction in GluR2/3 may represent an attempt to compensate for increased cell excitability, consistent with mechanisms underlying homeostatic plasticity.

\section{Introduction}

Natural development of the mammalian nervous system is an inherently fragile process easily disrupted by exogenous toxins. Nicotine is a neuroteratogen (Slotkin, 1998) commonly abused during pregnancy, with rates of pregnant smokers reaching $>30 \%$ in some countries (Nelson and Taylor, 2001). In utero nicotine exposure broadly impacts CNS development by binding to nAChRs that are expressed early and widely during gestation (Semba and Fibiger, 1988; Hellstrom-Lindahl et al., 1998). Chronic nicotine exposure paradoxically increases the number of nAChRs while simultaneously causing a prolonged desensitization state, or "functional loss," of receptors (Marks et al., 1983; Marks et al., 1985; Wonnacott et al., 1990; Gentry and Lukas, 2002).

Developmental nicotine exposure (DNE) interferes with central respiratory control in neonatal mammals (Campos et al., 2009), leading to serious physiologic consequences as evidenced by the increased incidence of central and obstructive apneas

\footnotetext{
Received Aug. 1, 2012; revised Dec. 14, 2012; accepted Dec. 20, 2012.

Author contributions: S.J.J., J.Q.P., and R.F.F. designed research; S.J.J., J.Q.P., and C.M.H. performed research; S.J.J. and C.M.H. analyzed data; S.J.J. and R.F.F. wrote the paper.

This work was supported by American Heart Association Grant AHA 0550062Z. We thank Seres J. Bennet Cross for outstanding technical assistance.

The authors declare no competing financial interests.

Correspondence should be addressed to Stuti J. Jaiswal, University of Arizona, College of Medicine, Department of Physiology, P.0. Box 210093, Tucson, AZ 84721-0093. E-mail: stuti@email.arizona.edu.

DOI:10.1523/JNEUROSCI.3711-12.2013

Copyright $\odot 2013$ the authors $\quad 0270-6474 / 13 / 332616-10 \$ 15.00 / 0$
}

(Kahn et al., 1994) and sudden infant death in neonates born to smoking mothers (Golding, 1997; Alm et al., 1998). Here, we examine how DNE changes excitatory neurotransmission in brainstem regions critical to normal breathing. These regions include the pre-Bötzinger Complex (pre-BötC), considered the "kernel" of inspiratory rhythm generation (Smith et al., 1991; Rekling and Feldman, 1998), and the hypoglossal motor nucleus (XIIMN), which provides motor output to tongue muscles during inspiration to maintain airway patency.

Fast excitatory neurotransmission in both regions depends on glutamatergic input partially mediated through the ionotropic AMPAR (Greer et al., 1991; Pace and Del Negro, 2008). Previous in vitro studies show that DNE enhances the frequency of respiratory-related phrenic motor nerve bursts in response to medullary bath application of AMPA (Pilarski and Fregosi, 2009). It was unclear in these studies which brainstem regions mediated this effect; here we hypothesize the pre-BötC is responsible for these observations. DNE also reduces excitatory synaptic input to XII motoneurons, consistent with diminished glutamate release secondary to desensitization of nAChRs on glutamatergic neurons projecting to the XIIMN (Pilarski et al., 2012). Therefore, an additional goal was to more closely examine how DNE affects AMPAergic neurotransmission in the XIIMN. We also hypothesized that the increased excitability observed in the respiratory system after DNE (Pilarski and Fregosi, 2009) resulted from a compensatory increase in AMPAR expression, as others show that gestational nicotine increases glutamate receptor expression in some brain regions (Wang et al., 2007). 

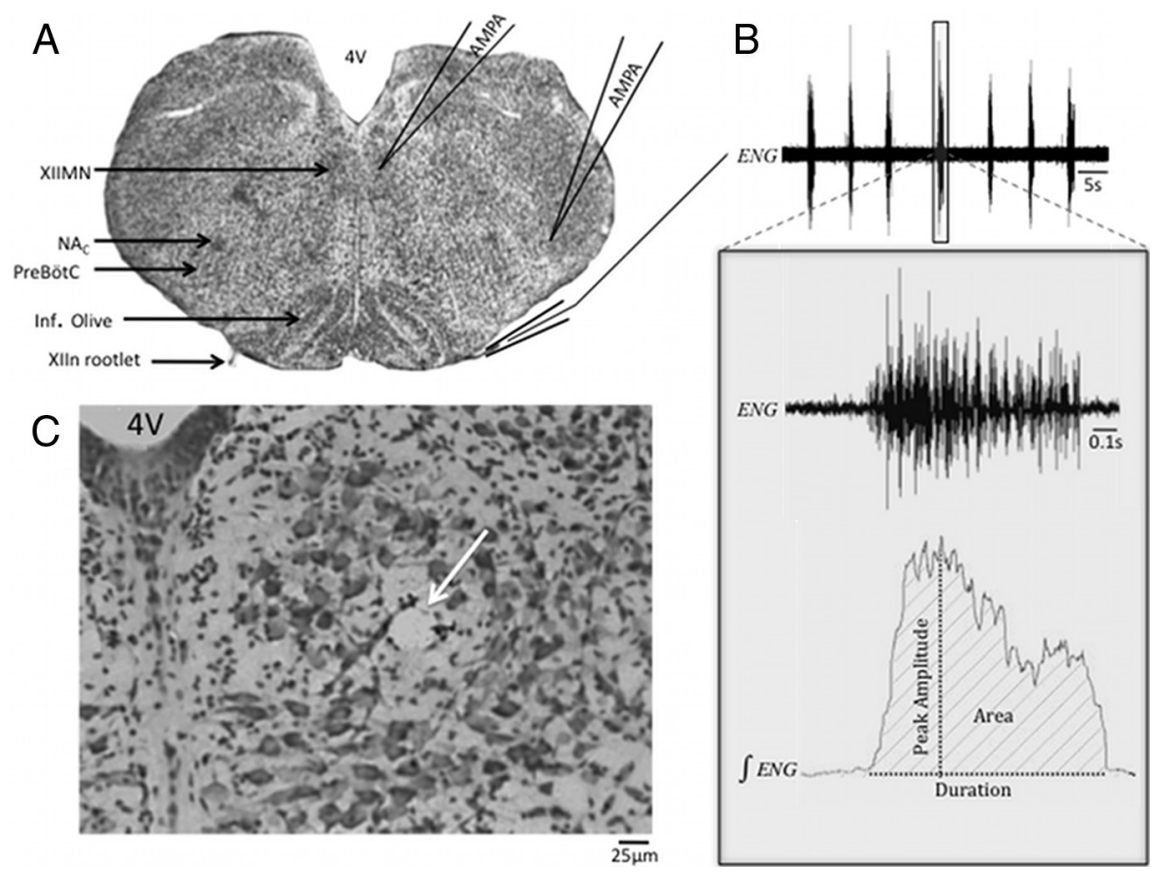

Figure 1. AMPA microinjection. $A$, Nissl-stained section with critical regions of interest highlighted on the left, and a diagram of pipette tip placement and the recording setup on the right. $4 \mathrm{~V}$, Fourth ventricle; Inf. Olive, Inferior Olive. $\boldsymbol{B}$, Representative electroneurogram (ENG) obtained from the XIIn; boxed region in the top panel is expanded below to show the raw and integrated representation of one respiratory-related XIIn burst. The variables measured for each of these bursts are denoted on the integrated ENG trace. Average amplitude (measurement not shown) was obtained by dividing the burst area by the burst duration. C, Example of a microinjection site (arrow) in the XIIMN in a Nissl-stained section (original magnification 20X).

Rhythmic brainstem slices provide a convenient model to investigate central respiratory control; slices contain the pre-BötC, part of the XIIMN, and premotor interneurons linking the two populations (Koshiya and Smith, 1999). These regions comprise a circuit where the pre-BötC drives respiratory burst frequency, and the XIIMN and premotoneurons modulate burst strength and pattern. We used this model to record XII nerve (XIIn) output (population activity) extracellularly and studied single XII motoneurons under whole-cell voltage and current clamp in neonatal rats to examine how DNE alters glutamatergic neurotransmission in the XIIMN and pre-BötC. AMPA was microinjected into these regions using single, brief pressure pulses. Finally, we used immunohistochemistry (IHC) to determine whether DNE changes AMPAR expression in these regions.

\section{Materials and Methods}

Animal usage, nicotine exposure, and preparation of

brainstem slices

Animal usage. All procedures and food/housing protocols were approved by the Institutional Animal Care and Use Committee at the University of Arizona. Every effort was made to reduce the number of animals necessary to assess treatment responses in this study. We used 58 neonatal rats of either sex obtained from 18 litters. The number of neonates used in each experiment is provided below.

Nicotine exposure. As described previously (Luo et al., 2004, 2007; Huang et al., 2010), pregnant Sprague Dawley rats were surgically implanted on gestational day 5 with subcutaneous osmotic mini-pumps (Alzet). The pumps were loaded to administer either nicotine bitartrate at a dose of $6 \mathrm{mg} / \mathrm{kg} / \mathrm{d}$ or physiologic saline (vehicle control) for $28 \mathrm{~d}$ after implantation. In addition to the saline and nicotine-exposed groups, we included an additional group in which the mother did not undergo any surgery or pump implantation (i.e., these were considered unexposed neonates). However, because no respiratory output differences were found between the two control groups, the data were combined into a single control group and will be referred to as such throughout the rest of this manuscript. Litters were born by spontaneous vaginal delivery and housed with the mother, who had free access to food and water, until experiments commenced. We studied neonates ranging in age from postnatal day 0 ( $\mathrm{P} 0)$ to $\mathrm{P} 5$. As the pump lasted for a week or more after delivery, neonates were exposed to nicotine in utero via the placenta, and via breast milk after birth.

Preparation of brainstem slices for microinjection experiments. Pups of either sex were randomly collected from their litters, sexed, and weighed. The average age of DNE animals ( $n=$ 15) was $2.5 \mathrm{~d}$, whereas the average age of control animals $(n=15)$ was $2.3 \mathrm{~d}$. Animals were anesthetized on ice until they were unresponsive to paw pinch, and quickly decerebrated at the coronal suture. After evisceration, the remaining CNS and the surrounding spinal column and ribcage were transferred to a dish containing modified, chilled $\left(4^{\circ} \mathrm{C}-8^{\circ} \mathrm{C}\right)$, and oxygenated $\left(95 \% \mathrm{O}_{2} / 5 \% \mathrm{CO}_{2}\right)$ aCSF solution (in mm: $120 \mathrm{NaCl}, 26 \mathrm{NaHCO}_{3}, 30$ glucose, 1 $\mathrm{MgSO}_{4}, 3 \mathrm{KCl}, 1.25 \mathrm{NaH}_{2} \mathrm{PO}_{4}, 1.2 \mathrm{CaCl}_{2}, \mathrm{pH} 7$. $4)$. The medulla and upper spinal cord were extracted and pinned to a cutting block, with the rostral surface up, for serial microsection slicing in a Vibratome (VT1000, Leica). Transverse medullary slices were taken until the rostral inferior olive and the most rostral hypoglossal nerve rootlet were near the surface. Rhythmic brainstem slices made in this manner are widely used and contain both the preBötC and XIIMN, which are the regions necessary for generating rhythmic motor bursts that can be recorded from hypoglossal nerve rootlets that are also retained in the slice (Ballanyi and Ruangkittisakul, 2009). Preparations were then transferred to a recording chamber, which was continuously perfused (rate, $4 \mathrm{ml} / \mathrm{min}$ ) with oxygenated and modified room temperature aCSF (in mM: $120 \mathrm{NaCl}, 26 \mathrm{NaHCO}_{3}, 30$ glucose, $1 \mathrm{MgSO}_{4}, 9 \mathrm{KCl}, 1.25 \mathrm{NaH}_{2} \mathrm{PO}_{4}, 1.2 \mathrm{CaCl}_{2}, \mathrm{pH}$ 7. 4). We used $9 \mathrm{~mm} \mathrm{KCl}$ in the recording solution to promote enhanced rhythmic bursting activity (Ren and Greer, 2008). Experimental preparations equilibrated in the recording solution for 20-30 min before recording.

\section{Series I: whole nerve recordings}

Glass suction electrodes were used to record XII motoneuron population activity from XII nerve rootlets. Slices were considered rhythmic upon the observation of consistent bursting activity (see Figs. 2 and 3). Rootlet activity was amplified, filtered $(100-3000 \mathrm{~Hz})$, digitized (Spike $2 \mathrm{~A} / \mathrm{D}$ board, CED), and stored on a computer (Dell) using Spike2 software (CED)

Microinjection of AMPA. Thick-walled borosilicate glass capillary tubes (OD $1.5 \mathrm{~mm}$, ID $0.75 \mathrm{~mm}$, Sutter Instruments) were pulled to tip sizes $\sim 1 \mu \mathrm{m}$ in diameter (resistance, 1.2-3.8 M ). Tips were filled with AMPA (Sigma), mixed daily from stock solution, connected to a picospritzer (Picospritzer II, General Valve), and mounted on a micromanipulator for injection; a stereomicroscope mounted above the recording chamber was used to visualize tip placement.

For XIIMN injections (Fig. 1), tips were placed at the surface of the slice at a slight angle near the visualized boundary of the XIIMN and then slowly advanced until the pipette tip was $35-40 \mu \mathrm{m}$ beneath the surface, near the center of the XIIMN column. The AMPA concentration used for XIIMN injections was $1 \mu \mathrm{M}$, mixed in the bathing solution. For pre-BötC microinjections, tips were placed at the surface of the ventrolateral region of the slice and advanced 25-30 $\mu \mathrm{m}$ beneath the surface to avoid significant damage to rhythm-generating neurons. The concentration of AMPA used for pre-BötC injections was $10 \mu \mathrm{M}$, mixed in the bathing solution. 
In both XIIMN and pre-BötC experiments, microinjection lasted for $5 \mathrm{~s}$ at 20 psi. Drug dosages and injection timings were selected based on pilot studies showing clearly measurable responses without abolition of the respiratory rhythm. Individual injection volumes were not obtained for each experiment, but we estimated injection volume by measuring the average distance traveled by the meniscus over multiple injections in several pipette tips pulled in the same manner as described above. The change in volume divided by the number of injections gave an estimated injection volume over the $5 \mathrm{~s}$ period of $16-25 \mathrm{nl}$.

XIIn rootlet activity was monitored during pipette tip placement in both the XIIMN and pre-BötC; there was no indication of altered nerve burst frequency or amplitude resulting from AMPA leakage. Vehicle injections (data not shown) containing the bathing solution were performed on 3 animals in both XIIMN and the pre-BötC as a control. In these experiments, electrode placement, timing, and injection pressure were identical to those described above. No changes in XIIn activity were noted, suggesting that the forthcoming data result from drug effects and not from mechanical stimulation secondary to pipette insertion or stimulation of cells with vehicle.

Nissl staining protocol. After microinjection experiments, slices were fixed in $4 \%$ paraformaldehyde in PBS, mounted on a chuck and placed in a Vibratome. Forty-micrometer-thick sections were mounted on glass slides and progressively dehydrated in 70\%, 95\%, and 100\% ethanol, and then cleared in xylenes. After progressive rehydration in the same solutions, sections were stained with cresyl violet, dehydrated, coverslipped, and examined with bright-field microscopy to confirm microinjection locations (Fig. 1).

\section{Series II: single-cell electrophysiology}

We examined individual XII motoneuron responses to AMPA microinjection in separate experiments using rhythmic brainstem slices prepared exactly as described above. Individual XII motoneurons were visualized using an Olympus BX-50WI fixed-stage microscope $(40 \times 0.75 \mathrm{NA}$ water-immersion objective) equipped with differential interference contrast optics and an infrared video camera (C25400-07, Hamamatsu), as described previously (Pilarski et al., 2011, 2012). Whole-cell recordings of XII motoneurons were made with glass pipettes (3-5 M $\Omega$ ) pulled from thick-walled borosilicate glass capillary tubes (OD $1.5 \mathrm{~mm}$, ID $0.75 \mathrm{~mm}$, Sutter Instruments). The patch pipettes for voltage-clamp experiments were loaded with a Cs-based solution containing the following (in $\mathrm{mm}$ ): $130 \mathrm{CsCl}, 5 \mathrm{NaCl}, 2 \mathrm{MgCl}_{2}, 1 \mathrm{CaCl}, 10$ HEPES, 2 ATP-Mg, 2 sucrose, with $\mathrm{pH}$ adjusted to 7.2 using $\mathrm{CsOH}$. Patch pipettes for current-clamp experiments were loaded with the following (in $\mathrm{mm}$ ): $140 \mathrm{~K}$-gluconate, $5 \mathrm{NaCl}$, $0.1 \mathrm{CaCl}_{2}, 1.1$ EGTA, 10 HEPES, 2 ATP $\left(\mathrm{Mg}^{2+}\right.$ salt), with $\mathrm{pH}$ adjusted to 7.2 and osmolarity adjusted to $250-275$ mOsm. Liquid junction potentials were adjusted to zero offset current before seal formation.

Cells were voltage-clamped at $-70 \mathrm{mV}$ and series resistance $\left(\mathrm{R}_{\mathrm{S}}\right)$ was monitored regularly without applying compensation. Cells exhibiting $R_{S}$ $>10 \%$ of the whole-cell input resistance $\left(\mathrm{R}_{\text {in }}\right)$ were not studied. During voltage-clamp experiments, tetrodotoxin ( $1 \mu \mathrm{M}$; Sigma $)$ was added to the bath to synaptically isolate cells from respiratory-related synaptic input. As described above, microinjection pipette tips were filled with $1 \mu \mathrm{M}$ AMPA mixed in the recording solution. From a holding potential of -70 $\mathrm{mV}$, we used microinjections (Picospritzer II) to deliver AMPA to XII motoneurons as described by others (Zaninetti et al., 1999; Chamberlin et al., 2002; Quitadamo et al., 2005). Microinjections were timed to occur between XIIn bursts, and parameters of the injection were identical to those described above, using a $5 \mathrm{~s}$ duration and a pulse pressure of $20 \mathrm{psi}$. The pipette tip (1.2-3.8 M $\Omega$ ) was consistently positioned $50 \mu \mathrm{m}$ from the motoneuron of interest. In two cells, we confirmed that AMPAevoked currents were fully suppressed by the AMPA antagonist CNQX (10 $\mu \mathrm{M}$, Sigma). We also studied a population of cells receiving rhythmic, respiration-related synaptic input under current clamp to obtain the spike frequency response to AMPA microinjection.

\section{Series III: immunohistochemistry experiments}

Neonates (P3 and P6) were anesthetized and transcardially perfused with $4 \%$ paraformaldehyde in PBS. Brainstems were rapidly removed and postfixed overnight in the perfusion solution. Fixed brainstems were
Table 1. Baseline measurements of XIIn burst duration and frequency ${ }^{a}$

\begin{tabular}{lclll}
\hline & XIIMN preinjection & $p$ & Pre-BötC preinjection & $p$ \\
\hline Duration (s) & & & & \\
$\quad$ Control & $0.651 \pm 0.0792$ & 0.3986 & $0.646 \pm 0.0354$ & 0.4528 \\
$\quad$ DNE & $0.718 \pm 0.0315$ & & $0.689 \pm 0.0434$ & \\
Frequency (bursts/min) & & & & \\
$\quad$ Control & $6.8 \pm 0.8$ & 0.7091 & $8.8 \pm 1.4$ & 0.2317 \\
$\quad$ DNE & $7.1 \pm 0.5$ & & $7.0 \pm 0.4$ &
\end{tabular}

${ }^{a}$ The average baseline burst duration and frequency were measured over a 2 min period immediately preceding AMPA injection into either the pre-BötC or XIIMN. No significant difference was found between control and DNE groups for either parameter or for either injection site.

glued to a chuck using the flattened pontine surface as the base and placed in a Vibratome. Transverse sections, cut at $40 \mu \mathrm{m}$ thickness, were taken through the medulla starting caudally at the spinomedullary junction and ending rostrally at approximately the pontomedullary junction.

To identify glutamate receptors, sections were mounted serially on electrostatic glass slides and blocked for $1 \mathrm{~h}$ in $0.25 \%$ BSA and $0.1 \%$ Triton X-100 in $0.1 \mathrm{M}$ PBS, pH 7.4. To minimize processing variability, sections from nicotine animals were mounted with anatomically corresponding sections from a control animal on the same slide. After removal from the blocking solution, sections were incubated overnight in a mixture containing the primary antibody (rabbit anti-GluR2/GluR3, Millipore, 1:2500) (Garcia Del Cano et al., 1999) and the blocking solution. After rinsing, sections were incubated in the host-appropriate biotinylated secondary antibody solution (dilution of 1:1000) for 8-12 h, followed by washing, and then incubation in avidin-biotin-HRP complex (Vector Laboratories, Elite kit). For visualization using DAB as the chromagen, slides were incubated in a $100 \mathrm{ml}$ of Tris buffer solution containing $50 \mathrm{mg}$ of $\mathrm{DAB}, 40 \mathrm{mg}$ of ammonium chloride, $0.3 \mathrm{mg}$ of glucose oxidase (Sigma), and $200 \mathrm{mg}$ of $\beta$ - $\mathrm{D}^{+}$-glucose.

\section{Data analysis and experiments}

Series I experiments. Data were analyzed using custom scripts created with Spike 2 software. We measured both tonic and spontaneous bursting activity from the XIIn recordings. The amplitude and duration of tonic activity were measured during the first two expiratory cycles after injection; these values were averaged and calculated as a percentage change from the baseline bursts recorded immediately before injection. Data from each slice preparation were averaged for each treatment group and subjected to a Student's $t$ test for statistical analysis.

To quantify rhythmic bursting activity, XIIn bursts were rectified and integrated digitally, and subjected to measurements of peak burst amplitude, burst duration, burst area, average burst amplitude (area/duration), and burst frequency (1/cycle period) before and after AMPA injection in both treatment groups (Fig. 1). All measurements were made for each burst during a baseline period of $2 \mathrm{~min}$ and for $8 \mathrm{~min}$ after drug injection. Given the variable nature of respiration-related motor output between individual rhythmic brainstem slices, burst characteristics were expressed as a percentage of the average measured during the baselinebursting period. Statistical analysis was performed on every burst in the 8 min postinjection interval, whereas average data are reported for the first 25 postinjection bursts for each parameter because the response had plateaued in all cases (e.g., see Figs. 3, 5, and 6). Data were averaged across all preparations, regions, and drug treatments. A two-way ANOVA (Prism, GraphPad) was used for statistical analysis of changes in burst characteristics between treatment groups. The main effects were treatment and postinjection burst number; $p$ values $<0.05$ were considered statistically significant.

Series II experiments. Current and voltage signals were amplified and acquired as previously described (Pilarski et al., 2011, 2012). Peak inward currents obtained from voltage-clamp experiments were analyzed with custom software programs written with Spike 2 software. The recovery time course was calculated as the time constant $(\tau)$, or time to return to $63 \%$ of the baseline current. Instantaneous spike frequency, obtained from current-clamp recordings, was also analyzed with custom software programs written with Spike 2 software. For statistical analysis, data were 


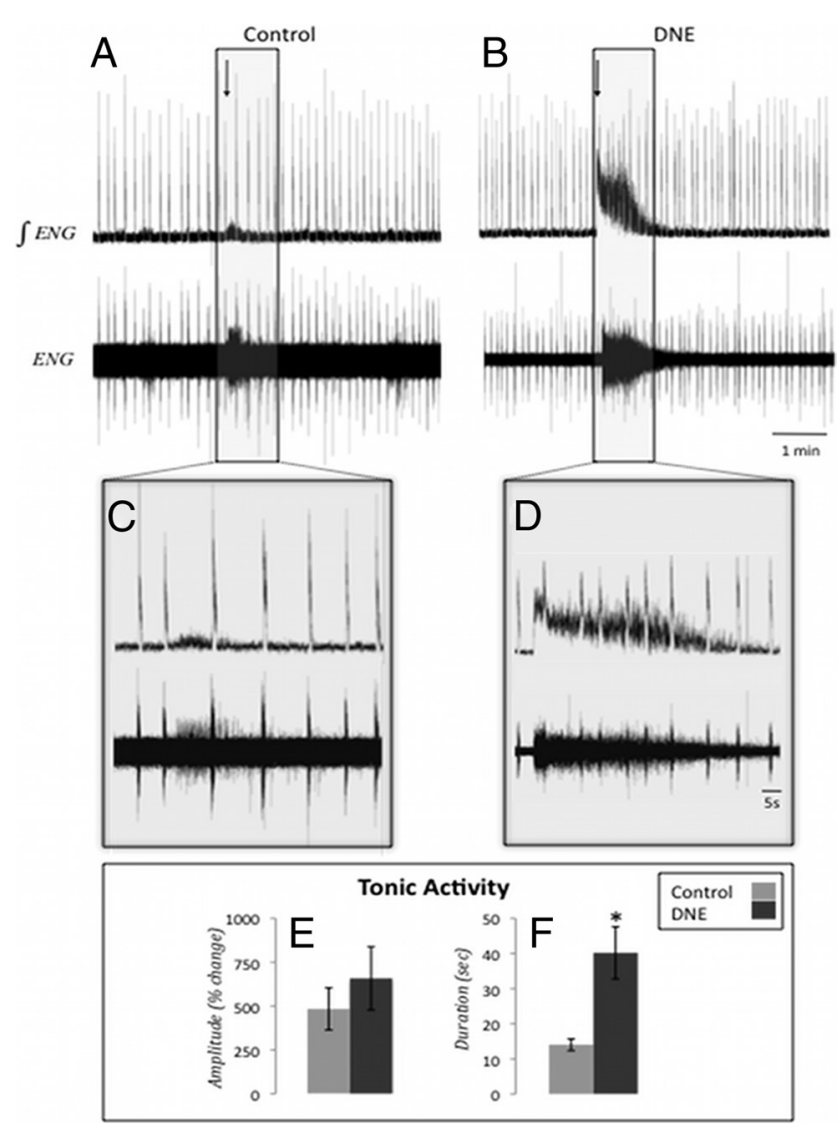

Figure 2. XIIn activity after AMPA microinjection into the XII motor nucleus. Representative traces of XIIn activity in a rhythmic brainstem slice before and after AMPA microinjection into the XIIMN. $A, B$, Raw (bottom) and integrated (top) traces from both control and DNE preparations before and after microinjection of $1 \mu \mathrm{m}$ AMPA into the XIIMN (arrow indicates injection start time). Boxed regions in $\boldsymbol{A}$ and $\boldsymbol{B}$ are expanded in $\boldsymbol{C}$ and $\boldsymbol{D}$, respectively. $\boldsymbol{E}$, Tonic activity amplitude, calculated as percentage change from the preinjection baseline for control and DNE preparations (control, $483.36 \pm 119.84 \%$; DNE, $658.11 \pm 180.43 \%$; $p=0.484$ ). The amplitude of tonic activity was measured in the periods between phasic XIIn bursts. $F$, Duration of increased tonic activity after AMPA injection in control and DNE preparations (control, $14.03 \pm$ $1.68 \mathrm{~s} ; \mathrm{DNE}, 40.18 \pm 7.43 \mathrm{~s} ; p=0.012$ ). Error bars represent SEM.

subjected to unpaired Student's $t$ tests. All data are presented as mean \pm SEM. Data are considered statistically significant if $p \leq 0.05$.

Series III experiments. Sections were visualized with a microscope, photographed under standardized lighting conditions, digitized, and analyzed using ImageJ software. In each section, $\sim 8-12$ cells in each region of interest (the pre-BötC region and both XIIMN) were selected from grayscale images, and the optical density of each cell was measured and recorded. Optical density comparisons of glutamate receptor subunits 2 and 3 (GluR2/3) expression were made between control and DNE sections mounted on the same slide to ensure that comparisons were between tissues that had been processed identically. The optical density of each cell was normalized against the background optical density, which was computed by averaging the staining density in 4 small regions that should theoretically not have had any staining. These normalized values were averaged and then compared between treatment groups using an unpaired Student's $t$ test.

\section{Results}

\section{Series I: whole nerve recordings}

Figure $1 A$ shows a representative Nissl-stained transverse section through the medulla with anatomic regions of interest and the basic experimental setup highlighted; a typical spontaneous respiratory burst from a XIIn recording is shown in Figure $1 B$, whereas a typical microinjection site is shown in Figure 1C. Av-

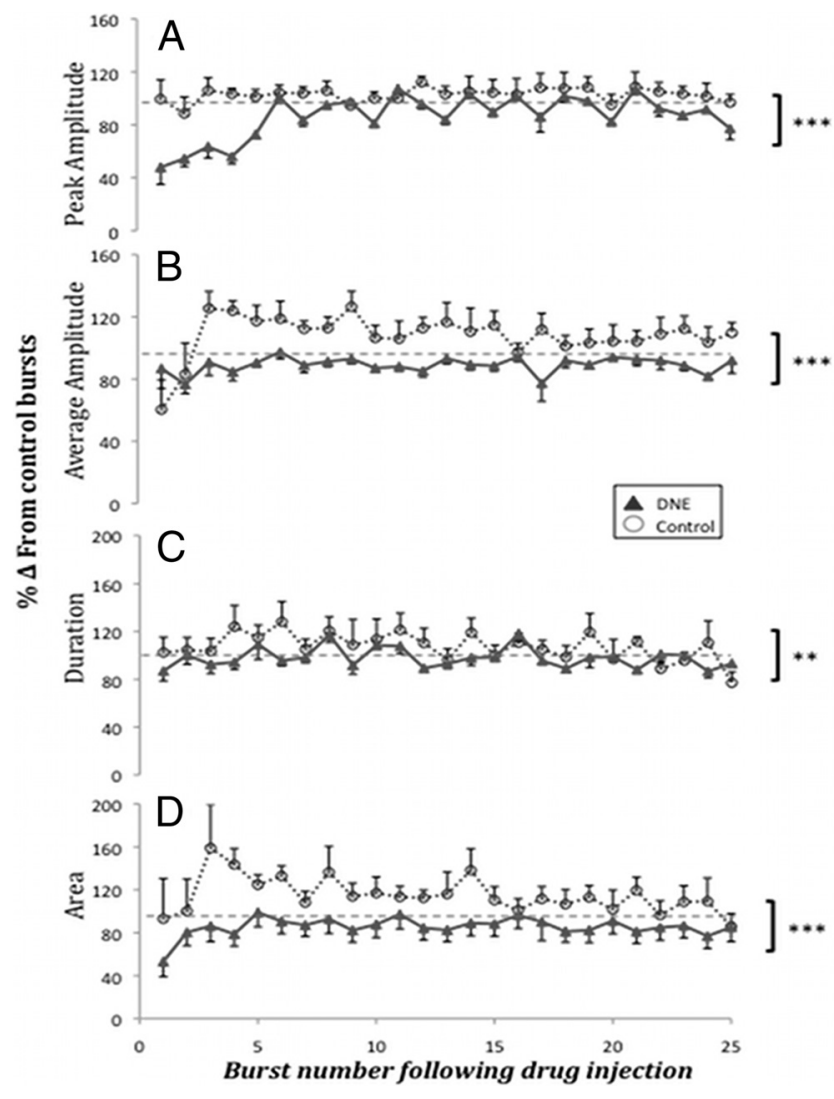

Figure 3. Burst characteristics in control and DNE slices after AMPA microinjection into the XIIMN. Comparisons of burst characteristics between control $(n=8)$ and DNE $(n=11)$ preparations for the first 25 postinjection bursts ( $1 \mu \mathrm{M}$ AMPA injected for $5 \mathrm{~s}$ ). Burst characteristics reported as the percentage change from baseline bursts averaged over a $2 \min$ period $(100 \%$, hyphenated line). Characteristics measured included the following. $A$, Peak burst amplitude. $\boldsymbol{B}$, Average burst amplitude. C, Burst duration. D, Burst area. ${ }^{* * *} p<0.0001$ (control vs DNE). ${ }^{* *} p<0.01$ (control vs DNE).

erage values of baseline bursting frequency and burst duration, neither of which were significantly different between treatment groups, are reported for both XIIMN and pre-BötC injections in Table 1.

Part A: DNE alters XIIn motor activity after AMPA injection into the XIIMN

Figure $2 A, B$ shows representative raw and integrated traces of XIIn burst activity before, during, and after AMPA microinjection $(1 \mu \mathrm{M}$ for $5 \mathrm{~s})$ into the XIIMN for both control and DNE preparations, respectively. Figure $2 C, D$ shows a section of these recorded responses on an expanded time base. We observed a substantial increase in tonic activity after AMPA injection in both treatment groups ( 7 of 8 control and 8 of 11 DNE preparations responded with increased tonic activity), but this effect was enhanced in the DNE preparations. For measurements of tonic XIIn amplitude and duration, we discarded data from one control and one DNE preparation because their values were $>2$ SDs above the group mean value. The amplitude of tonic activity (Fig. $2 E$ ) was not influenced by DNE (control, $483.4 \pm 119.8 \%$; DNE, $658.1 \pm 180.4 \% ; p=0.484)$, but the average duration of elevated tonic activity (Fig. $2 F$ ) was increased in DNE slices (control, $14.0 \pm 1.7 \mathrm{~s} ;$ DNE, $40.2 \pm 7.4 s ; p=0.012$ ).

Rhythmic XIIn bursts continued against the background of strong tonic discharge subsequent to AMPA microinjection and also continued after tonic firing had ceased. Analysis of individ- 


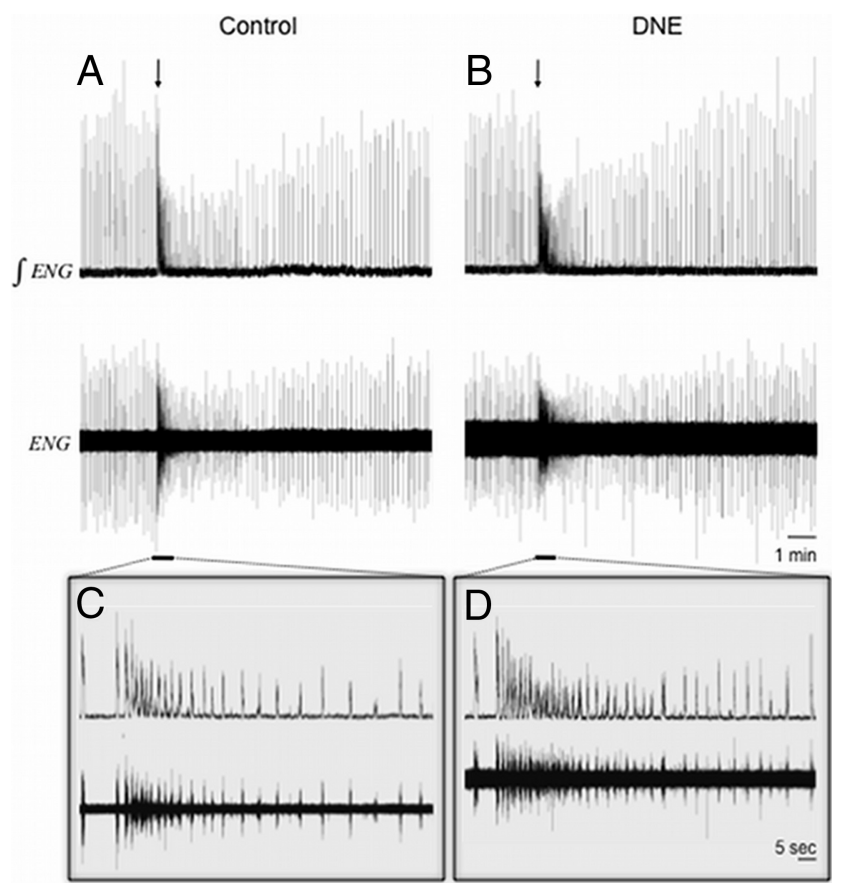

Figure 4. XIIn activity after AMPA microinjection into the pre-BötC region. Representative traces of XIIn activity in a rhythmic brainstem slice before and after AMPA microinjection into the pre-BötC region. $A$, Raw (bottom) and integrated (top) traces from both control and DNE preparations before and after microinjection of $10 \mu \mathrm{M}$ AMPA into the pre-BötC for $5 \mathrm{~s}$ (arrow indicates injection start time). Underlined regions in $\boldsymbol{A}$ and $\boldsymbol{B}$ are expanded in $\boldsymbol{C}$ and $\boldsymbol{D}$, respectively. Note that injection of AMPA increased nerve burst frequency in both control and DNE preparations and that the increase was greater in the DNE slices.

ual bursts subsequent to microinjection (see Materials and Methods section for a detailed description of the measurements) demonstrated significant differences in burst characteristics between control $(n=8)$ and DNE $(n=11)$ preparations (Fig. 3$)$. The first several bursts immediately after AMPA microinjection demonstrated a reduced peak burst amplitude in DNE animals compared with controls (Fig. 3A). Two-way ANOVA of the postinjection bursts showed that the difference between treatment groups was significant $(F=90.59, p<0.0001)$. Analysis of the average burst amplitude (Fig. $3 B$ ) showed slightly different results; after AMPA microinjection into the XIIMN, average burst amplitude was smaller in DNE slices than in controls $(F=$ $60.76, p<0.0001)$. AMPA microinjections also led to a significant treatment effect on burst duration (Fig. $3 C)(F=12.77$, $p=0.0004)$ and burst area (Fig. 3D) after AMPA microinjection $(F=102.74, p<0.0001)$. No significant interaction was found between treatment and postinjection burst number after injection for any of the parameters described in this section, indicating that the differences between treatment groups were independent of time after injection.

Part B: DNE alters XIIn motor activity after AMPA injection into the pre-BötC

AMPA microinjections ( $10 \mu \mathrm{M}$ for $5 \mathrm{~s}$ ) into the pre-BötC region evoked changes in the XIIn output of both control $(n=9)$ and DNE $(n=9)$ neonates. Figure 4 shows representative raw and integrated traces of XIIn activity before, during, and after AMPA microinjection for both control (Fig. 4A) and DNE (Fig. 4B) preparations, respectively, whereas Figure $4 C, D$ shows sections of the recorded response on an expanded time base. Note the increased burst frequency combined with progressively decreasing burst amplitude exhibited by both groups in response to
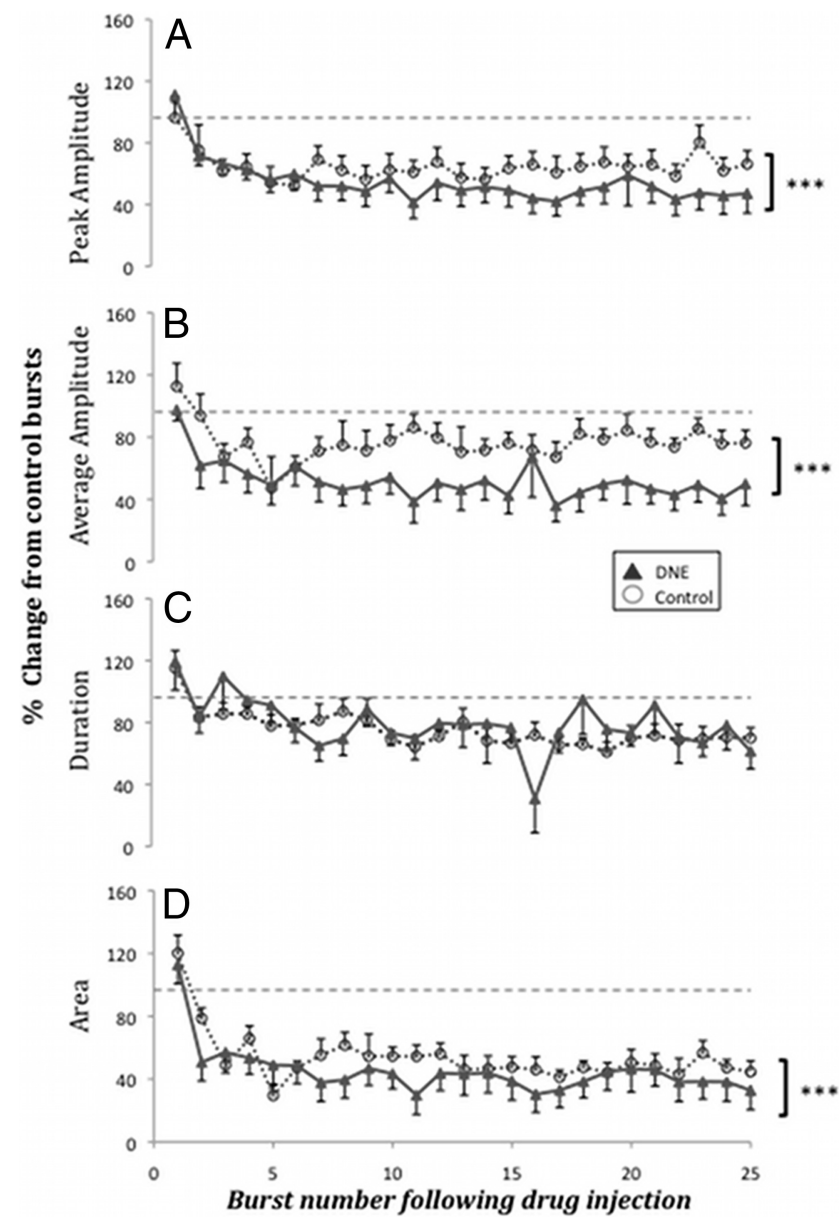

Figure 5. Burst characteristics in control and DNE after AMPA microinjection into the preBötC region. Comparisons of burst characteristics between control $(n=9)$ and DNE $(n=9)$ for the first 25 postinjection bursts ( $10 \mu \mathrm{m}$ AMPA injected for $5 \mathrm{~s}$ ). Burst characteristics reported as percentage change from preinjection baseline values that were averaged over a 2 min period (100\%, hyphenated line). Characteristics measured included the following. $A$, Peak burst amplitude. $\boldsymbol{B}$, Average burst amplitude. C, Burst duration. $\boldsymbol{D}$, Burst area. ${ }^{* * *} p<0.0001$ (control vs DNE).

AMPA. No tonic discharge was observed after AMPA microinjection into the pre-BötC region, but peak burst amplitude (Fig. $5 A$ ) decreased over the first several postinjection bursts, with DNE preparations showing a more exaggerated response versus control $(F=87.35, p<0.0001)$. Analysis of average burst amplitude (Fig. $5 B$ ) shows similar results; both control and DNE slices demonstrated decreased average burst amplitude with an enhanced response observed in DNE animals $(F=361.04, p<$ 0.0001). Burst duration (Fig. $5 C$ ) did not differ significantly between control and DNE preparations after AMPA microinjection in the pre-BötC region, whereas burst area (Fig. 5D) declined slightly, but significantly, more in DNE animals compared with controls $(F=152.88, p<0.0001)$. We did not find a significant interaction between treatment group and time after injection for any of the measured parameters, indicating that the differences between treatment groups were independent of time after injection.

Part C: effect of DNE on AMPA-mediated control of respiratory rhythm generation

The baseline XIIn burst frequency measured over a $2 \mathrm{~min}$ period before drug injection did not differ between control and DNE slices, as shown in Table 1. Microinjection of AMPA into the 


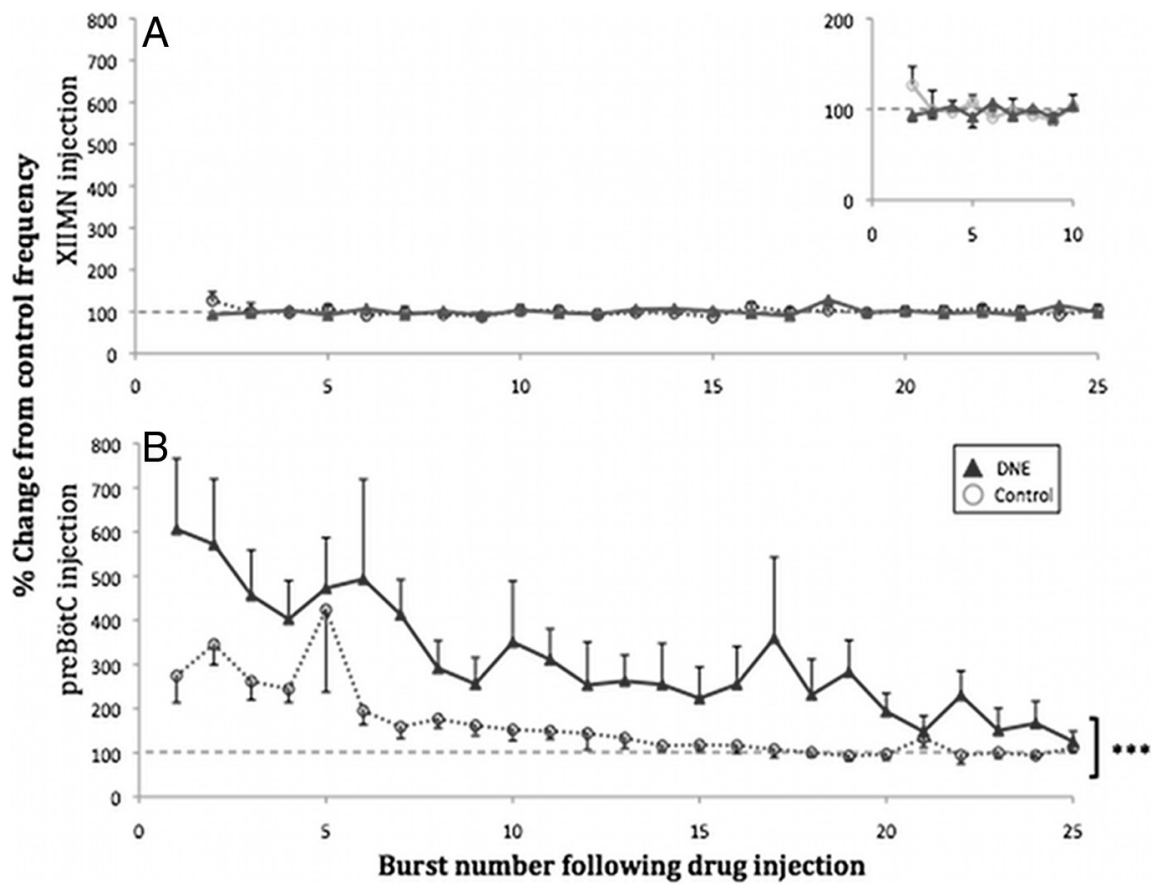

Figure 6. Changes in burst frequency after AMPA microinjection into XIIMN and pre-BötC region. Frequency of XIIn bursts for the first 25 postinjection bursts is reported as percentage change from the average burst frequency in the 2 min preinjection period (100\%, hyphenated line). $\boldsymbol{A}$, Comparison of spontaneous bursting frequency between control $(n=8)$ and DNE $(n=11)$ after XIIMN microinjections (1 $\mu$ M AMPA, 5 s). Inset, The same graph on an expanded time scale for the first 10 bursts for a more detailed comparison. $\boldsymbol{B}$, Comparisons of spontaneous bursting frequency between control $(n=9)$ and DNE $(n=9)$ after pre-BötC microinjections (10 $\mu \mathrm{MAMPA}, 5 \mathrm{~s}) .{ }^{* * *} p<0.0001$ (control vs DNE).

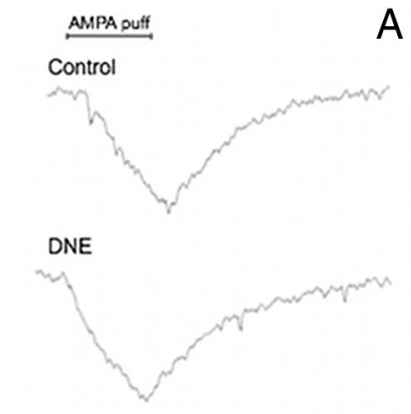

A

B
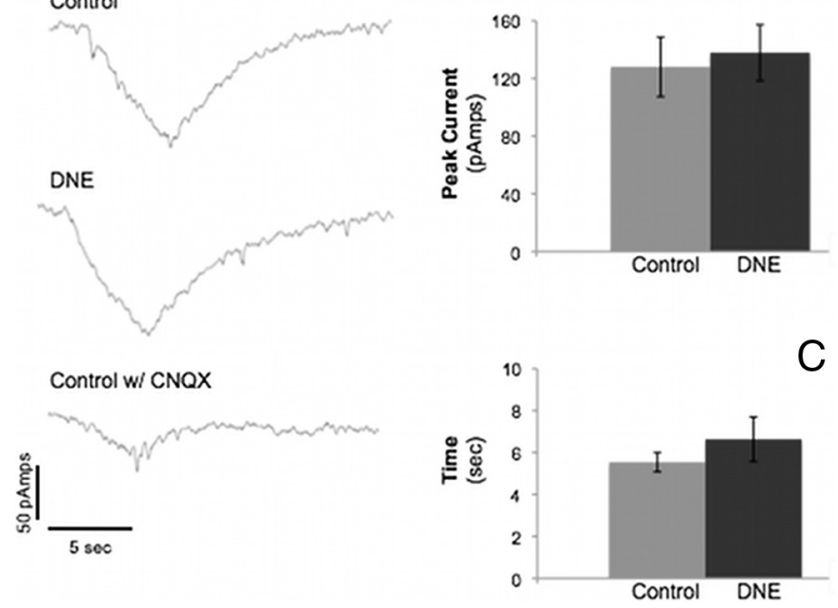

Figure 7. Peak inward current and recovery time constant of XII motoneurons after AMPA microinjection. Voltage-clamp data from hypoglossal motoneurons in rhythmic brainstem slices from control and DNE preparations. A, Representative traces of inward currents obtained from control and DNE hypoglossal motoneurons in response to microinjection of $1 \mu \mathrm{M}$ AMPA at a distance of $50 \mu \mathrm{m}$ from the recorded cell. Bottom, Response of a control motoneuron to the AMPA puff, but in the presence of $10 \mu \mathrm{M} C \mathrm{CNX}$, an AMPA receptor antagonist. CNQX blocked the majority of the response, indicating that the currents were AMPA-mediated. B, $C$, Average peak inward currents and recovery time constant in neurons from both treatment groups (control, $n=10$ cells; DNE, $n=14$ cells). No significant differences were found between treatment groups for either peak inward current or the recovery time constant.

XIIMN did not elicit a significant change in burst frequency (Fig. $6 A$ ) in either control or DNE preparations, supporting literature suggesting that XII motoneurons do not contribute to the generation of inspiratory rhythm (Funk and Feldman, 1995). In con- trast, AMPA injection into the pre-BötC significantly increased burst frequency (Fig. 6B) in both groups, with DNE animals demonstrating a larger increase compared with controls $(F=48.67, p<$ $0.0001)$. There was also a significant dependence of frequency on postinjection burst number $(F=4.26, p<0.0001)$, as bursting frequency was consistently higher immediately after AMPA microinjection, but the magnitude of the difference diminished with time.

\section{Series II: effects of AMPA on XII motoneuron inward currents and spike frequency}

The changes in XIIn output subsequent to AMPA injection into the XIIMN led us to test this same treatment on the voltage and current responses of single XII motoneurons to gain insight into the effects of DNE on these cells. Voltage-clamp experiments were used to compare inward currents from control and DNE animals in response to AMPA microinjection (Fig. 7). Figure $7 A$ (top two traces) shows representative currents obtained from control and DNE animals. Voltage-clamp recordings were done in 14 control cells and 10 DNE cells. No significant differences in AMPA-evoked peak inward current (Fig. $7 B$ ) were found between control and DNE preparations (control, $128.1 \pm 20.6 \mathrm{pA}$; DNE, $137.9 \pm 19.5 \mathrm{pA}$ ). We also measured the recovery time constant (time to $63 \%$ of recovery, Fig. $7 C$ ) of the inward current and found no difference between treatment groups. Figure $7 A$ (bottom trace) is an example of the current response to AMPA from a control preparation in the presence of CNQX, which largely abolished the inward current, suggesting that the response is mediated by AMPA receptors.

We found that the average instantaneous spike frequency (Fig. $8 A, B$ ) of current-clamped cells (control, $n=12$ cells; DNE, $n=$ 7 cells) in response to AMPA microinjection was higher in DNE versus control cells (DNE, $18.4 \pm 1.5 \mathrm{~Hz}$; control, $7.2 \pm 1.1 \mathrm{~Hz}$; Student's $t$ test: $p<0.0001)$. Spiking in response to AMPA injection was not observed in 3 of the 12 control cells measured, but all DNE cells responded with brisk spiking activity. Another phenomenon observed in response to AMPA injection in a few cells was depolarization block subsequent to intense membrane depolarization (Fig. 8C). Depolarization block was observed in only 1 of 12 control cells ( $8 \%$ ) but 3 of 7 DNE cells (43\%).

\section{Series III: effects of DNE on glutamate}

receptor immunohistochemistry

IHC was used to probe the XIIMN and pre-BötC (Fig. 9) for GluR2/3 in an effort to semiquantitatively examine the influence of DNE on receptor expression in neurons contained within these regions. We considered an individual slide, containing serial sections from one control and one DNE brainstem as a single comparison. Across all comparisons, we studied 448 cells from control preparations and 466 cells from DNE preparations.

Figure 10 exhibits the details of these comparisons. For the P3 age group, four of five comparisons showed significantly more GluR2/3 than DNE motoneurons (Fig. 10), whereas in the P6 
group, only one of three comparisons showed a treatment effect. In cells from the pre-BötC region (Fig. 10 for details) three of four comparisons in the $\mathrm{P} 3$ age group showed significantly greater GluR2/3 expression in control than in DNE cells. However, in the P6 age group, there were no differences between groups in receptor expression in any of the three comparisons.

\section{Discussion}

We studied postnatal, DNE-induced changes in AMPA-type, glutamatergic neurotransmission in the XIIMN and the pre-BötC, two regions considered critical to respiratory control. Electrophysiological findings showed that DNE increases AMPAergic excitability of neurons in the XIIMN and the pre-BötC. Interestingly, excitatory inward currents in XII motoneurons in response to AMPA microinjection were not different between treatment groups. Moreover, IHC experiments indicate that DNE decreases GluR2/3 subunit expression in the XIIMN and the pre-BötC. These combined findings suggest that the DNE-mediated reduction in AMPAR expression may be an adaptive response aimed at mitigating the DNE-induced enhancement of neuronal excitability.

\section{Critique of methods}

Our model simulates in utero nicotine exposure in pregnant women and allows us to examine its influence on respiratory circuit neurons. The osmotic mini-pumps steadily release nicotine into the bloodstream, consistent with studies suggesting that tobacco users selftitrate nicotine intake to constant levels (Ebert et al., 1984; Woodward and Tunstall-Pedoe, 1993; Fu et al., 2011). Using nicotine alone bypasses the confounding effects of other chemicals found in cigarettes while also avoiding the animal stress that occurs with repeated smoke exposure (Suemaru et al., 1992). We used $28 \mathrm{~d}$ osmotic pumps implanted on gestational day 5; pups were exposed to nicotine via the placenta throughout the remainder of gestation, and via breast milk after birth. Whether nicotine dosage differs between that received through the placenta and breast milk is unknown, although breast milk likely contains less (Stepans and Wilkerson, 1993).

Rhythmic brainstem slices are a useful in vitro model for examining activity in respiratory-related neurons (Feldman and Del Negro, 2006). This preparation supplies an isolated system that provides a measurable, respiratory-related fictive motor output, which can be manipulated externally to determine the effects of various drugs and environments on respiratory rhythm generation and the output of respiratory muscle motoneurons. As with any in vitro system, in vivo responses cannot be assumed, as the slice lacks normal efferent and afferent inputs. Nonetheless, the model is extremely useful for examining the impact of DNE on neuronal function.

We designed our IHC experiments to minimize variability in antibody concentration and exposure times, and variability bebars, $25 \mu \mathrm{m}$.
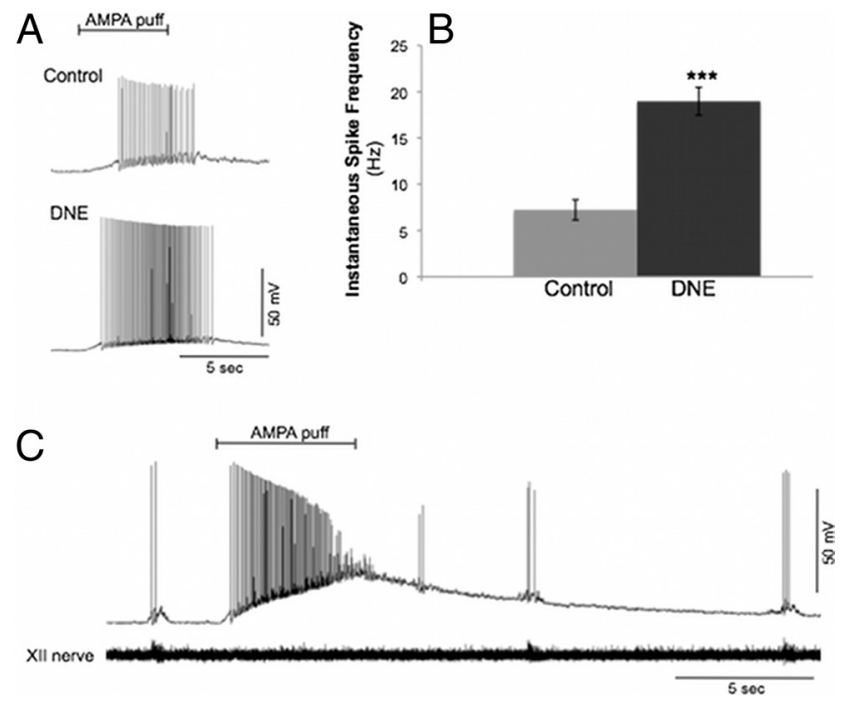

Figure 8. Spike frequency in XII motoneurons after AMPA microinjection. Current-clamp recordings from control and DNEXII motoneurons from rhythmic brainstem slices in response to AMPA injection into the XIIMN (control, $n=12$ cells; DNE, $n=7$ cells). $\boldsymbol{A}$, Representative current-clamp recordings from a control and DNE XII motoneuron (spike frequency, control, 7.9 $\mathrm{Hz}$; and DNE, $18.4 \mathrm{~Hz}$ ). $\boldsymbol{B}$, Average spike frequency data obtained from all cells in response to AMPA puff. ${ }^{* * *} p<0.0001$ (control vs DNE). C, Example of a current-clamp recording obtained from a rhythmically active XII motoneuron that demonstrated a large increase in $V_{m}$ in response to AMPA injection, leading to depolarization block.
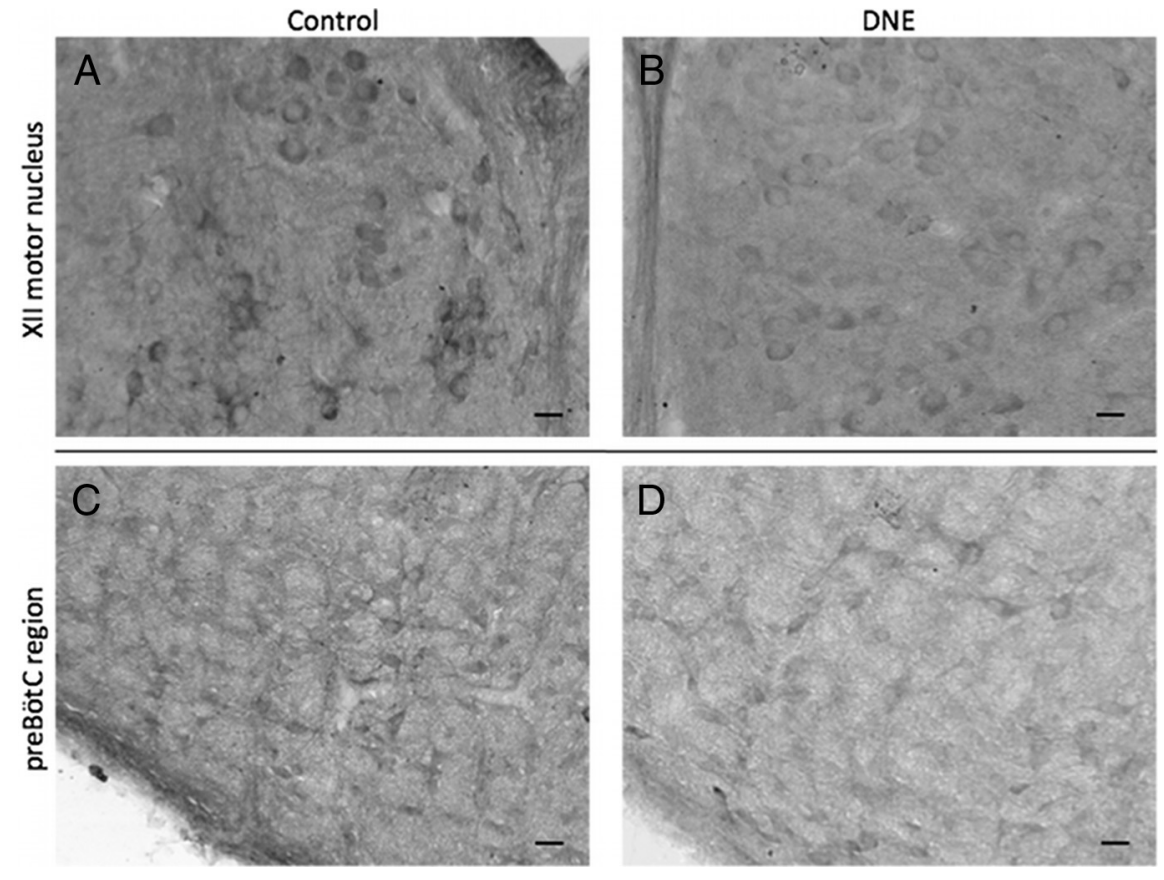

Figure 9. GluR2/3 immunohistochemistry in XIIMN and pre-BötC. $A, B$, Example images of GluR2/3 IHC in the hypoglossal motor nucleus of DNE $(\boldsymbol{A})$ and control $(\boldsymbol{B})$ neonates. $\boldsymbol{C}$, $\boldsymbol{D}$, Example images of GluR2/3 IHC in the pre-BötC of DNE $(\boldsymbol{C})$ and control animals $(\boldsymbol{D})$. Original magnification $\times 20$. Brainstems from a control and DNE animal were sectioned, fixed, and mounted on the same day (see Materials and Methods), and $40-\mu \mathrm{m}$-thick sections from each treatment group were mounted on the same slide and processed identically. Optical density measurements of each cell were normalized against background staining of individual sections (see Materials and Methods). Note the darker staining in control versus DNE cells in both XIIMN and pre-BötC regions. Scale tween animals, allowing for a semiquantitative measurement of relative protein expression between control and DNE neurons. Of note, the AMPAR is a tetrameric protein (Wollmuth and Sobolevsky, 2004) composed of subunits GluR1-GluR4, whereas 


\begin{tabular}{|c|c|c|c|c|c|c|}
\hline \multicolumn{7}{|c|}{ Immunohistochemistry Analysis } \\
\hline Age & Region & Comparison & $\begin{array}{l}\text { \# of cells } \\
\text { control/DNE }\end{array}$ & $\begin{array}{c}O D \\
\text { Control }\end{array}$ & $\begin{array}{l}\text { OD } \\
\text { DNE }\end{array}$ & $P$ value \\
\hline \multirow[t]{6}{*}{ P3 } & $X I I M N$ & & & & & \\
\hline & & 1 & $45 / 39$ & 2.89 & 1.98 & $.0462^{*}$ \\
\hline & & 2 & $39 / 40$ & 1.70 & 0.99 & $<.0001^{\cdots} \cdot$ \\
\hline & & 3 & $39 / 41$ & 3.29 & 3.53 & .5464 \\
\hline & & 4 & $37 / 42$ & 3.29 & 2.4 & $.0162^{*}$ \\
\hline & & 5 & $40 / 40$ & 3.97 & 3.07 & $.0401^{*}$ \\
\hline \multirow[t]{4}{*}{ P6 } & $X I M N$ & & & & & \\
\hline & & 1 & $37 / 40$ & 2.93 & 2.240 & $.0406^{*}$ \\
\hline & & 2 & $38 / 42$ & 3.58 & 3.505 & .8702 \\
\hline & & 3 & $37 / 42$ & 5.47 & 6.22 & .2136 \\
\hline \multirow[t]{5}{*}{ P3 } & preBötc & & & & & \\
\hline & & 1 & $17 / 19$ & 2.08 & 1.80 & .2913 \\
\hline & & 2 & $19 / 20$ & 2.22 & 3.30 & .0727 \\
\hline & & 3 & $20 / 20$ & 3.043 & 1.688 & $.0204^{*}$ \\
\hline & & 4 & $20 / 21$ & 2.353 & 1.785 & $.0368^{*}$ \\
\hline \multirow[t]{4}{*}{ P6 } & prebotc & & & & & \\
\hline & & 1 & $21 / 20$ & 2.21 & 1.69 & .0567 \\
\hline & & 2 & $20 / 20$ & 2.37 & 1.98 & .3513 \\
\hline & & 3 & $19 / 20$ & 1.85 & 1.56 & .3112 \\
\hline
\end{tabular}

Figure 10. Optical density comparisons in the XII motor nucleus and pre-BötC of control and DNE neonates. Average optical density (OD) in neurons from $\mathrm{P} 3$ and $\mathrm{P} 6$ neonates in both the XIIMN and pre-BötC regions. Control and DNE columns contain the average optical density measurements, reported as grayscale pixilation per unit area (see Materials and Methods). The number of cells examined in each control and DNE animal are given in the fourth column. Each comparison represents brainstem slices from a single control and DNE animal, which were mounted and processed on the same slide (see Materials and Methods).

the antibody used here probes for GluR subunits 2 and 3. The influence of DNE on receptor expression appears age dependent, with DNE having larger effects on P3 than on P6. This may result from a postnatal reduction in nicotine dosage as pups transition from blood to breast milk exposure, possibly indicating that some effects of nicotine are reversible if exposure stops postnatally.

\section{Influence of AMPA microinjection in the XIIMN and pre-BötC on XIIn activity}

Smoking mothers expose their fetuses to chronic doses of nicotine, which has a far-reaching impact on the CNS via stimulation of nAChRs. Presynaptic nAChRs are located on virtually all inhibitory and excitatory interneurons and modulate neurotransmitter release when activated (for review see Wonnacott, 1997; Gentry and Lukas, 2002). We initially hypothesized that DNE, by desensitizing nAChRs (Fregosi and Pilarski, 2008), reduces presynaptic glutamate release, leading to a compensatory increase in AMPAR expression on the postsynaptic membrane of neurons involved in respiratory control. This theory was based on previous studies performed in brainstem-spinal cord preparations that demonstrated enhanced respiratory frequency responses to AMPA in DNE preparations (Pilarski and Fregosi, 2009). Support for this model came from findings showing that DNE reduced the frequency of glutamatergic EPSCs in XII motoneurons (Pilarski et al., 2011) but increased the response of phrenic mo- toneurons to AMPA applied to the medulla (Pilarski and Fregosi, 2009). Here, we assessed how two specific medullary regions, both crucial for normal breathing, responded to AMPA exposure after DNE.

AMPA microinjection into the XIIMN indicated a complicated effect on respiratory motor output. We observed an increase in tonic activity duration but a decrease in XIIn burst amplitude and duration over the first several postinjection bursts. Importantly, AMPA microinjection into the XIIMN did not change burst frequency, indicating that microinjections were focal and that AMPA did not diffuse to regions involved in frequency control.

In contrast, AMPA microinjection into the pre-BötC increased XIIn burst frequency for both groups but with DNE slices exhibiting an enhanced response. Burst characteristics, such as amplitude and area, progressively decreased, likely because the high-frequency cycling reduced the total number of action potentials per burst, or that fewer motoneurons were recruited. These observations support literature identifying the pre-BötC as a frequency generator whereas motoneuron pools modulate burst pattern (Funk and Feldman, 1995).

\section{Influence of AMPA on XII motoneuron activity}

Voltage-clamp recordings showed no difference in AMPAmediated inwards currents between groups, whereas currentclamp recordings of XIIMNs demonstrated that DNE increases motoneuron excitability. This is based on our findings of increased spike frequency and the increased incidence of depolarization block in DNE cells after AMPA injection. The latter observation may explain the overall reduction of XIIn phasic burst amplitude after AMPA injection into the XIIMN. Depolarization block likely results from sodium channel inactivation because of the large, AMPA-evoked depolarization. Pilot studies suggested that the occurrence of depolarization block depended on the distance between the motoneuron and the microinjection pipette tip. We propose that neurons closer to the injection experienced frank depolarization block, whereas neurons farther away continued to fire. These studies suggest that DNE augments the effects of AMPA on XIIMNs, as predicted from previous work on phrenic motoneurons (Pilarski and Fregosi, 2009).

\section{Potential mechanisms}

We hypothesized that DNE increases AMPAR expression, but measurements of inward currents after AMPA injection show no difference between treatment groups. Moreover, immunohistochemical assessment of GluR2/3 showed reduced expression in both XIIMNs and the pre-BötC in DNE animals. Possibilities explaining this paradox include differential subunit expression of GluRs, changes in cell morphology, or modification of ionic conductances.

Although we show that DNE decreases GluR2/3 subunit expression in the XIIMN and pre-BötC, which suggests a decrease in AMPAR expression, Wang et al. (2011) showed that DNE increases hippocampal GluR1 expression. Thus, we cannot exclude the possibility that DNE modifies GluR subunit expression in a differential manner that does not alter total receptor numbers on the postsynaptic membrane. Additionally, we did not observe any treatment effects on AMPA-evoked inward currents of XII motoneurons, which are expected if receptor numbers change significantly, making differential receptor expression a more plausible explanation.

One possibility that would reconcile decreased AMPAR expression with increased cell excitability is that DNE changes neu- 
ronal morphology. We did not systematically measure cell size here because in our recent studies we showed that DNE increases input resistance in XII motoneurons (Pilarski et al., 2011), consistent with reduced cell size. These previous experiments examined XII motoneurons in thin, nonrhythmic slices that lacked the large amount of synaptic input normally present in motoneurons from rhythmically active slices, thereby allowing accurate measurement of input resistance. Confocal microscopy studies initiated in our laboratory are expected to provide more definitive results of DNE-induced changes in cell volume, dendritic branching patterns, and receptor location.

Previous studies also show that DNE steepens the frequency response to injected current (Pilarski et al., 2011) in XII motoneurons, suggesting a change in either cell size, as discussed above, or changes in ion channel conductances. Others show that chronic and acute nicotine exposure can affect ionic currents that potentially underlie cell excitability. Buttigieg et al. (2009) showed that DNE upregulates ATP-sensitive $\mathrm{K}^{+}$channels in rat adrenomedullary chromaffin cells, and Griguoli et al. (2010) posit that acute nicotine directly blocks ion channels that carry inwardly rectifying, mixed $\left(\mathrm{Na}^{+}\right.$and $\left.\mathrm{K}^{+}\right) I_{\mathrm{H}}$ currents that help set excitability in cells exhibiting oscillatory behavior (Yanagihara and Irisawa, 1980; Bayliss et al., 1994; Thoby-Brisson et al., 2000). DNE may alter the regulation of these channels to effectively increase neuronal excitability. Nicotine's impact on the ionic conductances that maintain the respiratory network, however, remains relatively unstudied.

We propose that DNE increases neuronal excitability and leads some XII motoneurons and pre-BötC interneurons to change AMPAR expression in a compensatory manner. Although DNE altered the response to AMPA injection into the XIIMN and pre-BötC, baseline bursting did not differ between groups, consistent with compensation for elevated excitability. The reduction in AMPAR expression may represent an adaptive response to the enhancement of cell excitability, a mechanism akin to homeostatic plasticity (Turrigiano, 2008; Pozo and Goda, 2010). The role of AMPARs in synaptic scaling is well studied, and regulation of specific AMPAR subunits plays an important part in synaptic plasticity (Isaac et al., 2007). DNE-induced modifications of AMPAR subunit expression, as demonstrated here in brainstem neurons, could have serious physiologic consequences for developing neonates.

In conclusion, our experiments contribute to an increasing body of literature showing that DNE alters development of brainstem respiratory neurons. Although most studies, including ours, show that DNE does not alter baseline-breathing characteristics in newborn mammals, their impaired ventilatory response to critical stressors, such as hypoxia, is well documented (Hafstrom et al., 2005). This suggests that homeostatic neuronal compensation may not always mitigate the nicotine-induced alteration of normal neuronal development.

\section{References}

Alm B, Milerad J, Wennergren G, Skjaerven R, Oyen N, Norvenius G, Daltveit AK, Helweg-Larsen K, Markestad T, Irgens LM (1998) A case-control study of smoking and sudden infant death syndrome in the Scandinavian countries, 1992 to 1995: the Nordic Epidemiological SIDS Study. Arch Dis Child 78:329-334. CrossRef Medline

Ballanyi K, Ruangkittisakul A (2009) Structure-function analysis of rhythmogenic inspiratory pre-Botzinger complex networks in "calibrated" newborn rat brainstem slices. Respir Physiol Neurobiol 168:158-178. CrossRef Medline

Bayliss DA, Viana F, Bellingham MC, Berger AJ (1994) Characteristics and postnatal development of a hyperpolarization-activated inward current in rat hypoglossal motoneurons in vitro. J Neurophysiol 71:119-128. Medline

Buttigieg J, Brown S, Holloway AC, Nurse CA (2009) Chronic nicotine blunts hypoxic sensitivity in perinatal rat adrenal chromaffin cells via upregulation of KATP channels: role of $\alpha 7$ nicotinic acetylcholine receptor and hypoxia-inducible factor- $2 \alpha$. J Neurosci 29:7137-7147. CrossRef Medline

Campos M, Bravo E, Eugenín J (2009) Respiratory dysfunctions induced by prenatal nicotine exposure. Clin Exp Pharmacol Physiol 36:1205-1217. CrossRef Medline

Chamberlin NL, Bocchiaro CM, Greene RW, Feldman JL (2002) Nicotinic excitation of rat hypoglossal motoneurons. Neuroscience 115:861-870. CrossRef Medline

Ebert RV, McNabb ME, Snow SL (1984) Effect of nicotine chewing gum on plasma nicotine levels of cigarette smokers. Clin Pharmacol Ther 35: 495-498. CrossRef Medline

Feldman JL, Del Negro CA (2006) Looking for inspiration: new perspectives on respiratory rhythm. Nat Rev Neurosci 7:232-242. CrossRef Medline

Fregosi RF, Pilarski JQ (2008) Prenatal nicotine exposure and development of nicotinic and fast amino acid-mediated neurotransmission in the control of breathing. Respir Physiol Neurobiol 164:80-86. CrossRef Medline

Fu M, Martínez-Sanchez JM, Agudo A, Pascual JA, Borràs JM, Samet JM, FernándezE (2011) Association between time to first cigarette after waking up and salivary cotinine concentration. Nicotine Tob Res 13:168-172. CrossRef Medline

Funk GD, Feldman JL (1995) Generation of respiratory rhythm and pattern in mammals: insights from developmental studies. Curr Opin Neurobiol 5:778-785. CrossRef Medline

Garcia Del Caño G, Millán LM, Gerrikagoitia I, Sarasa M, Matute C (1999) Ionotropic glutamate receptor subunit distribution on hypoglossal motoneuronal pools in the rat. J Neurocytol 28:455-468. CrossRef Medline

Gentry CL, Lukas RJ (2002) Regulation of nicotinic acetylcholine receptor numbers and function by chronic nicotine exposure. Curr Drug Targets CNS Neurol Disord 1:359-385. CrossRef Medline

Golding J (1997) Sudden infant death syndrome and parental smoking: a literature review. Paediatr Perinat Epidemiol 11:67-77. CrossRef Medline

Greer JJ, Smith JC, Feldman JL (1991) Role of excitatory amino acids in the generation and transmission of respiratory drive in neonatal rat. J Physiol 437:727-749. Medline

Griguoli M, Maul A, Nguyen C, Giorgetti A, Carloni P, Cherubini E (2010) Nicotine blocks the hyperpolarization-activated current Ih and severely impairs the oscillatory behavior of oriens-lacunosum moleculare interneurons. J Neurosci 30:10773-10783. CrossRef Medline

Hafström O, Milerad J, Sandberg KL, Sundell HW (2005) Cardiorespiratory effects of nicotine exposure during development. Respir Physiol Neurobiol 149:325-341. CrossRef Medline

Hellström-Lindahl E, Gorbounova O, Seiger A, Mousavi M, Nordberg A (1998) Regional distribution of nicotinic receptors during prenatal development of human brain and spinal cord. Brain Res Dev Brain Res 108:147-160. Medline

Huang YH, Brown AR, Cross SJ, Cruz J, Rice A, Jaiswal S, Fregosi RF (2010) Influence of prenatal nicotine exposure on development of the ventilatory response to hypoxia and hypercapnia in neonatal rats. J Appl Physiol 109:149-158. CrossRef Medline

Isaac JT, Ashby MC, McBain CJ (2007) The role of the GluR2 subunit in AMPA receptor function and synaptic plasticity. Neuron 54:859-871. CrossRef Medline

Kahn A, Groswasser J, Sottiaux M, Kelmanson I, Rebuffat E, Franco P, Dramaix M, Wayenberg JL (1994) Prenatal exposure to cigarettes in infants with obstructive sleep apneas. Pediatrics 93:778-783. Medline

Koshiya N, Smith JC (1999) Neuronal pacemaker for breathing visualized in vitro. Nature 400:360-363. CrossRef Medline

Luo Z, Costy-Bennett S, Fregosi RF (2004) Prenatal nicotine exposure increases the strength of GABA(A) receptor-mediated inhibition of respiratory rhythm in neonatal rats. J Physiol 561:387-393. CrossRef Medline

Luo Z, McMullen NT, Costy-Bennett S, Fregosi RF (2007) Prenatal nicotine exposure alters glycinergic and GABAergic control of respiratory frequency in the neonatal rat brainstem-spinal cord preparation. Respir Physiol Neurobiol 157:226-234. CrossRef Medline

Marks MJ, Burch JB, Collins AC (1983) Effects of chronic nicotine infusion on tolerance development and nicotinic receptors. J Pharmacol Exp Ther 226:817-825. Medline 
Marks MJ, Stitzel JA, Collins AC (1985) Time course study of the effects of chronic nicotine infusion on drug response and brain receptors. J Pharmacol Exp Ther 235:619-628. Medline

Nelson EA, Taylor BJ (2001) International Child Care Practices Study: infant sleep position and parental smoking. Early Hum Dev 64:7-20. CrossRef Medline

Pace RW, Del Negro CA (2008) AMPA and metabotropic glutamate receptors cooperatively generate inspiratory-like depolarization in mouse respiratory neurons in vitro. Eur J Neurosci 28:2434-2442. CrossRef Medline

Pilarski JQ, Fregosi RF (2009) Prenatal nicotine exposure alters medullary nicotinic and AMPA-mediated control of respiratory frequency in vitro. Respir Physiol Neurobiol. 169:1-10. CrossRef Medline

Pilarski JQ, Wakefield HE, Fuglevand AJ, Levine RB, Fregosi RF (2011) Developmental nicotine exposure alters neurotransmission and excitability in hypoglossal motoneurons. J Neurophysiol 105:423-433. CrossRef Medline

Pilarski JQ, Wakefield HE, Fuglevand AJ, Levine RB, Fregosi RF (2012) Increased nicotinic receptor desensitization in hypoglossal motor neurons following chronic developmental nicotine exposure. J Neurophysiol 107: 257-264. CrossRef Medline

Pozo K, Goda Y (2010) Unraveling mechanisms of homeostatic synaptic plasticity. Neuron 66:337-351. CrossRef Medline

Quitadamo C, Fabbretti E, Lamanauskas N, Nistri A (2005) Activation and desensitization of neuronal nicotinic receptors modulate glutamatergic transmission on neonatal rat hypoglossal motoneurons. Eur J Neurosci 22:2723-2734. CrossRef Medline

Rekling JC, Feldman JL (1998) Pre-Botzinger complex and pacemaker neurons: hypothesized site and kernel for respiratory rhythm generation. Annu Rev Physiol 60:385-405. CrossRef Medline

Ren J, Greer JJ (2008) Modulation of perinatal respiratory rhythm by GABA(A)- and glycine receptor-mediated chloride conductances. Adv Exp Med Biol 605:149-153. CrossRef Medline

Semba K, Fibiger HC (1988) Time of origin of cholinergic neurons in the rat basal forebrain. J Comp Neurol 269:87-95. CrossRef Medline

Slotkin TA (1998) Fetal nicotine or cocaine exposure: which one is worse? J Pharmacol Exp Ther 285:931-945. Medline

Smith JC, Ellenberger HH, Ballanyi K, Richter DW, Feldman JL (1991) Pre-
Botzinger complex: a brainstem region that may generate respiratory rhythm in mammals. Science 254:726-729. CrossRef Medline

Stepans MB, Wilkerson N (1993) Physiologic effects of maternal smoking on breast-feeding infants. J Am Acad Nurse Pract 5:105-113. CrossRef Medline

Suemaru K, Oishi R, Gomita Y, Saeki K, Araki Y (1992) Effect of long-term cigarette smoke exposure on locomotor activity and brain monoamine levels in rats. Pharmacol Biochem Behav 41:655-658. CrossRef Medline

Turrigiano G (2008) The self-tuning neuron: synaptic scaling of excitatory synapses. Cell 135:422-435. CrossRef Medline

Thoby-Brisson M, Telgkamp P, Ramirez JM (2000) The role of the hyperpolarization-activated current in modulating rhythmic activity in the isolated respiratory network of mice. J Neurosci 20:2994-3005. Medline

Wang F, Chen H, Steketee JD, Sharp BM (2007) Upregulation of ionotropic glutamate receptor subunits within specific mesocorticolimbic regions during chronic nicotine self-administration. Neuropsychopharmacology 32:103-109. CrossRef Medline

Wang H, Dávila-Garcia MI, Yarl W, Gondré-Lewis MC (2011) Gestational nicotine exposure regulates expression of AMPA and NMDA receptors and their signaling apparatus in developing and adult rat hippocampus. Neuroscience 188:168-181. CrossRef Medline

Wollmuth LP, Sobolevsky AI (2004) Structure and gating of the glutamate receptor ion channel. Trends Neurosci 27:321-328. CrossRef Medline

Wonnacott S (1997) Presynaptic nicotinic ACh receptors. Trends Neurosci 20:92-98. CrossRef Medline

Wonnacott S, Drasdo A, Sanderson E, Rowell P (1990) Presynaptic nicotinic receptors and the modulation of transmitter release. Ciba Found Symp 152:87-101; discussion 102-105. Medline

Woodward M, Tunstall-Pedoe H (1993) Self-titration of nicotine: evidence from the Scottish Heart Health Study. Addiction 88:821-830. CrossRef Medline

Yanagihara K, Irisawa H (1980) Inward current activated during hyperpolarization in the rabbit sinoatrial node cell. Pflugers Arch 385:11-19. CrossRef Medline

Zaninetti M, Tribollet E, Bertrand D, Raggenbass M (1999) Presence of functional neuronal nicotinic acetylcholine receptors in brainstem motoneurons of the rat. Eur J Neurosci 11:2737-2748. CrossRef Medline 